\title{
De la demanda a la prefiguración. Historia del derecho a la ciudad en América Latina
}

From Demands to Prefiguration. History of the Right

to the City in Latin America

Da demanda à prefiguração. História do direito

à cidade na América Latina

Leandro Minuchin*

Recibido: 12 de noviembre de 2018

Aprobado: 15 de febrero de 2019

Doi: http://dx.doi.org/10.12804/revistas.urosario.edu.co/territorios/a.6363

Para citar este artículo:

Minuchin, L. (2019). De la demanda a la prefiguración. Historia del derecho a la ciudad en América Latina. Territorios, (41), 271-294. Doi: http://dx.doi.org/10.12804/revistas.urosario.edu.co/territorios/a.6363

* Profesor en arquitectura y urbanismo en la Escuela de Arquitectura de Manchester, Universidad de Manchester (Reino Unido). Licenciado en Ciencia Politica por la Universidad Nacional de Rosario (Argentina), magister en Estudios Latinoamericanos por la Universidad de Salamanca (España), magister en Modernidad, Espacio y Lugar y doctor en Geografia, ambos por la University College of London (Reino Unido). Correo electrónico: leandro.minuchin@manchester. ac.uk ORCID: http://orcid. org/0000-0003-2773-1367 
Palabras clave

Derecho a la ciudad, América Latina, prefiguración, autogestión, articulación.

Keywords

Right to the city, Latin America, prefiguration, self-organization, articulation.

Palavras-chave

Direito à cidade, América Latina, prefiguração, autogestão, articulação.

\section{territarias 41}

\section{RESUMEN}

El artículo presenta un aporte para trazar una historia conceptual del derecho a la ciudad en América Latina. Partiendo de una lectura crítica de la obra de Lefebvre, el ensayo reconstruye los marcos teóricos que acompañaron las actualizaciones prácticas del derecho a la ciudad en la región. El artículo abarca un periodo que se abre con la publicación del texto de Lefebvre en 1968 y se cierra con el declive de la "nueva izquierda" latinoamericana. Se argumenta que, durante este lapso, el derecho a la ciudad asume tres grandes configuraciones, en las que las apropiaciones colectivas y las traslaciones a la esfera de las políticas públicas son acompañadas por desplazamientos teóricos singulares. En una primera instancia movimientista, el derecho a la ciudad es utilizado para describir formas de acción colectiva atravesadas por el problema de la vivienda y la injusticia espacial. En una segunda configuración, signada por la apropiación institucional-burocrática del término, se transfiguran las proposiciones conceptuales presentadas por Lefebvre y se posiciona al derecho a la ciudad como significante vacío y marco para articular políticas públicas urbanas. En una tercera y reciente configuración, el derecho a la ciudad se actualiza para describir la emergencia de un nuevo repertorio de acción colectiva centrado en la noción de prefiguración, que vincula la construcción de territorios e infraestructuras sociales autónomas con la emergencia de nuevas prácticas políticas urbanas.

\section{ABSTRACT}

The article sets out to trace a conceptual history of the right to the city in Latin America. Based on a critical reading of Lefebvre's work, the essay reconstructs the theoretical frameworks that accompany the practical transformations of the right to the city in the region. The paper covers a period that starts with the publication of the book in 1968 and finishes with the decline of "the new left" in Latin America. The essay argues that, over this period, there are three different configurations of the right to the city, in which distinct theoretical displacements accompany the appropriations made by social movements and its inclusion into public policy arenas. During a first instance, associated with social movements, the notion is used to describe forms of collective action associated with housing and spatial injustice. A second configuration is marked by an institutional and bureaucratic appropriation, where Lefebvre's original conceptual coordinates transfigured. The right to the city is presented as an empty signifier and articulation emerges as a distinct political practice. In a third more recent configuration, social movements and collectives linked to social architecture actualize the notion of the right to the city around issues of construction and prefiguration.

\section{RESUMO}

O artigo apresenta um aporte para traçar uma história conceitual do direito à cidade na América Latina. Partindo de uma leitura crítica da obra de Lefebvre, o ensaio reconstrói os marcos teóricos que acompanharam as atualizações práticas do direito à cidade na região. $\mathrm{O}$ artigo abarca um período que se abre com a publicação do texto de Lefebvre em 1968 e fecha-se com o declive da 'nova esquerda' latino-americana. Argumenta-se que, durante este lapso, o direito à cidade assume três grandes configurações, onde as apropriações coletivas e translações à esfera das 
políticas públicas são acompanhadas por deslocamentos teóricos singulares. Em uma primeira instancia movimentista, o direito à cidade é utilizado para descrever formas de ação coletiva atravessadas pelo problema da vivenda e a injustiça espacial. Em uma segunda configuração, marcada pela apropriação institucional-burocrática do termo, se transfiguram as proposições conceituais apresentadas por Lefebvre e posiciona-se ao direito à cidade como significante vazio e marco para articular políticas públicas urbanas. Em uma terceira e recente configuração, o direito à cidade se atualiza para descrever a emergência de um novo repertório de ação coletiva centrado na noção de prefiguração, que vincula à construção de territórios e infraestruturas sociais autónomas com a emergência de novas práticas políticas urbanas.

\section{Aportes para una historiografía del derecho a la ciudad en Latinoamérica}

Acusando un desplazamiento conceptual y contextual de sus orígenes disruptivos, una multiplicidad de acepciones y adaptaciones del derecho a la ciudad circulan por Latinoamérica (Carrión \& Erazo, 2016). Movilizadas por una plétora de actores y movimientos que buscan enmarcar y dar sentido a una serie heterogénea de intervenciones y prácticas urbanas, las diferentes enunciaciones del derecho a la ciudad contienen en su seno intencionalidades y posicionamientos políticos antagónicos (Brenner, Marcuse \& Mayer, 2012). En torno al derecho a la ciudad se dirime una disputa por su significación que, lejos de quedar limitada a un mero arreglo y juego discursivo, se despliega en formas opuestas de entender la acción colectiva, la producción del espacio urbano y la capacidad para experimentar con arreglos sociomateriales más justos para habitar la ciudad (Harvey, 2012).

En esta disputa por la significación del derecho a la ciudad, el riesgo es la dilución y la erosión de sentido: extender los márgenes del concepto para que incluya todo y nada a la vez (Schmid, 2011). Las consignas proponen tanto iniciativas para extender las formas de representación liberal, como el llamado a la participación directa en la producción de soluciones habitacionales, y tanto inscribir la consagración simbólica de la propiedad social, como recuperar el valor de uso del espacio y suelo urbano (Fernandes, 2007; Rolnik, 2013). Con el afán de divulgar la consagración del derecho a la ciudad, se proclaman tanto imaginaciones vinculadas con la sostenibilidad urbana y ciudades inteligentes, como la recuperación de vínculos ancestrales con la naturaleza $(\mathrm{Su}-$ granyes, 2010).

La región ha estado, desde la irrupción del concepto en 1968, a la vanguardia por la búsqueda de formas y medios para avanzar en la materialización del derecho a la ciudad (Rodríguez, 2009). Este derecho funcionó en la región tanto como un dispositivo teórico capaz de iluminar la emergencia y transformación de los repertorios disponibles para la producción del espacio urbano, como una consigna territarios 41

273 
programática de agrupaciones y movimientos sociales urbanos.

El presente artículo es un aporte teórico-historiográfico que interroga las formas de abordar las actualizaciones significantes del derecho a la ciudad en la región. El ensayo plantea que las mutaciones del término se legitiman a partir de la consolidación de marcos interpretativos en principio antagónicos, que se articulan a partir del entrelazamiento de los marcos conceptuales y prácticas organizacionales y sociales aplicados para materializar el derecho a la ciudad. El ensayo sugiere que la consolidación de estos puede reconstruirse como una serie de actualizaciones teóricas que acompañan y dan sentido a las apropiaciones prácticas del término. El artículo argumenta que el derrotero histórico de los marcos interpretativos del derecho a la ciudad no puede ser presentado como un proceso evolutivo. En cambio, se propone leerlo como un proceso de tensión interpretativa, con marcos que se alejan y otros que revisan las contribuciones originales presentadas por Henri Lefebvre. Con el fin de ilustrar dichos desplazamientos, se parte de una revisión teórica de su obra y se examina la forma en que los conceptos de autogestión, desmercantilización (o descomodificación) y experimentación, centrales en la construcción de la noción del derecho a la ciudad, fueron incorporados, extendidos o ignorados por movimientos sociales urbanos, agencias públicas de planificación y gobiernos latinoamericanos. El ensayo sostiene que durante el periodo que se abre con la publicación y traducción del texto de Lefebvre a finales de la década del 60 y se cierra con la consolidación de las nuevas expresiones de izquierda a comienzos de siglo, el derecho a la ciudad asume tres grandes configuraciones. En una primera instancia, que se puede denominar como movimientista, el derecho a la ciudad fue utilizado para describir los repertorios desplegados por colectivos urbanos para entrelazar el problema de la vivienda y la injusticia espacial con experiencias autonómicas y experimentos de autogestión. En una segunda configuración signada por la apropiación institucional-burocrática del término, el derecho a la ciudad adquiere peso normativo: se transfiguran las proposiciones conceptuales presentadas por Lefebvre, se fuerza el reposicionamiento del Estado como agente central de transformación urbana y el término es utilizado — siguiendo a Laclau — como un significante vacío para inscribir a la articulación como práctica política, imponer una agenda programática y contener la creciente dispersión de demandas sociales en las metrópolis latinoamericanas. En una tercera configuración, que emerge con fuerza como expresión de los movimientos antiausteridad del nuevo siglo y las críticas regionales a las políticas neoliberales, el derecho a la ciudad se entrelaza con un proceso de repolitización de las prácticas constructivas y de materialización autónomas. En las ciudades latinoamericanas se despliegan prácticas de acción e intervención colectiva que buscan prefigurar, a través de la construcción de nuevas espacialidades, formas de lo social no mediadas 
por la lógica de acumulación de capital, que rompen con la temporalidad inherente de las políticas públicas y experimentan con la potencialidad de los recursos y saberes disponibles en el presente. La prefiguración delimita una nueva configuración del derecho a la ciudad, en donde se disloca el rol de la institucionalidad pública y se recupera el rol de los actores sociales — sus lógicas de intervención y temporalidaden la producción de lo común y de la ciudad (Dinerstein, 2014; Sitrin, 2014).

\section{El derecho a la ciudad: valor de uso, autogestión y lo posible}

La publicación de El derecho a la ciudad, traducida y editada en español de su versión francesa de 1968, por Península en 1969, marca un punto de condensación en la obra de Lefebvre, en la que los intereses teóricos vinculados con la politicidad de la vida cotidiana y la singularidad de los procesos urbanos de la segunda mitad del siglo XX sirven para cristalizar contenidos de una filosofía de la praxis en donde el terreno de la ciudad se abre, de manera simultánea, como soporte para discursos del orden y la acumulación y medio para la invención y transformación (Lefebvre, 1978).

En el derecho a la ciudad se entrecruzan tres ejes conceptuales que le permiten a Lefebvre enhebrar una descripción y una crítica del advenimiento de la sociedad urbana, en donde los procesos asociados con el tejido de las ciudades articulan modos de producción y formas de sociabilidad. El primer nodo conceptual giró en torno a la noción de autogestión. En un intento por cuestionar la prominencia atribuida en el marxismo clásico a la subordinación de la dinámica del suelo urbano a condicionamientos económicos estructurales (Lefebvre, 1976), Lefebvre retoma en el texto, una proposición que había presentado en un texto breve sobre autogestión publicado en 1966. Para Lefebvre, la autogestión representa un medio a partir del cual rescatar la potencialidad de arreglos sociales destinados a alterar patrones establecidos de producción y organización, y a "interrumpir", desde los márgenes, el funcionamiento "de la sociedad toda, una metamorfosis completa de la vida" (Lefebvre, 1976, p. 147). La autogestión en Lefebvre presupone una revisión de las formas de participación de la producción del espacio urbano y un señalamiento sobre la necesidad de facilitar el involucramiento de la comunidad en el gobierno de territorios más allá de la instancia de representación liberal: desde la autogestión de saberes a la invención y control de los bienes y servicios necesarios para la reproducción de la vida cotidiana, Lefebvre asoció a la autogestión con una instancia de disrupción y la utilizó como un momento fundacional, inaugural de la nueva política urbana. El derecho a la ciudad amplía la lógica de participación democrática, que incide en la definición de regulaciones y reglamentaciones y propicia el acceso a la administración de los soportes e infraestructuras vinculadas con la producción de la vida urbana y del territorio (Merrifield, 2014). tersitarios 41 275 
La autogestión se entrelaza con el segundo nodo presentado por la necesidad de acelerar un proceso de descomodificación o desmercantilización en las lógicas de producción del espacio urbano y recuperar el valor de uso. La descomodificación llama a inscribir modalidades de posesión alternativas, descomponer la primacía de la propiedad privada como instrumento exclusivo para pensar el desarrollo urbano y remarcar la importancia de ligar la territorialidad y la espacialidad de prácticas cotidianas con la creación de una 'obra' no organizada por valores de cambio (Lefebvre, 2003). "La generalización de la mercancía por obra de la industrialización tiende a destruir la ciudad y la realidad urbana, refugios del valor de uso" (Lefebvre, 1978, p. 20). Retomando las discusiones que lo habían acercado a los situasionistas en la década del 60 (Swyngedouw, 2002), el foco en la desmercantilización del espacio es un intento por proyectar formas de habitar que no estén mediadas por lógicas del intercambio monetario, la acumulación y el consumo. La primacía del valor de cambio, a los ojos de Lefebvre, había conseguido desplazar a los sectores populares de los centros urbanos y erosionada su capacidad para utilizar el espacio de la ciudad como un medio para proyectar otros patrones de sociabilidad.

El tercer nodo conceptual que atraviesa el derecho a la ciudad es la presentación de la ciudad como 'obra': como un terreno abierto a lo utópico y lo experimental. En el derecho a la ciudad, Lefebvre define lo urbano como una unidad prácticotemporal singular, en la cual "el pasado, presente y lo posible, no se separan" (Lefebvre, 1978, p. 125) y en donde se entremezclan la ciudad "inmediata, dato práctico sensible, arquitectónico [con] lo urbano, realidad social, compuesta por relaciones a concebir, a construir" (Lefebvre, 1978 , p. 67). A la ciudad regida por una instrumentalidad racional, reconfigurada como plataforma para nuevas instancias de acumulación, Lefebvre contrapone la figura del devecho a la ciudad como una forma de legitimar la experimentación en un territorio incompleto, en donde el espacio público deviene una plataforma para el encuentro y el fomento de nuevas espacialidades y relaciones sociales. El derecho a la ciudad, desglosa una nueva temporalidad urbana, en que el desenvolvimiento de la subjetividad urbana está atado a la transformación del espacio y viceversa. El derecho a la ciudad, en este sentido, tiene coordenadas ideológicas rígidas - particularmente en lo referido al llamado por recuperar el valor de uso de los suelos- pero sumamente abierta en los instrumentos, mecanismos y arreglos posibles para su concreción. Lo incompleto no designa una ausencia de definición o carencia de sentido, sino una determinación ontológica, en la que la experimentación se presenta como una dimensión constitutiva tanto de los sujetos urbanos, como del espacio en sí. Esa idea de ciudad futura dibujada por Lefebvre, lejos de proyectarse como una utopía inmaterial, se actualiza permanentemente a 
partir de la experimentación con lo "práctico-sensible" y la acumulación de saberes que de ella se desprenden como una serie encadenada de momentos sociopolíticos dirigida programáticamente a restablecer la primacía del valor de uso del espacio.

\section{El derecho a la ciudad y los movimientos sociales urbanos}

El derecho a la ciudad se moviliza para simplificar la finalidad de una pluralidad de actores urbanos que encuentran en ella la plataforma para configurar nuevas demandas sociales, y fue revisada y estudiada con avidez en círculos académicos y políticos en Perú, Brasil y Argentina (Nuñez, 2009). La aceleración de los procesos de urbanización en América Latina -en parte incorporadas en el texto de Lefebvre- dejó al descubierto las limitaciones de las maquinarias estatales para contener acelerados procesos de diferenciación social. La consolidación de nuevas lógicas de exclusión y marginalización vinculadas con la producción del suelo urbano propició la aparición de nuevas subjetividades urbanas que desplegaron nuevas formas de acción colectiva: ocupaciones de tierras organizadas, demandas vinculadas con el suelo, la vivienda y el acceso a servicios en contextos de fuertes migraciones rural-urbanas. Las discusiones entabladas entre Castells, con su noción de los movimientos sociales urbanos, y Lefebvre sirvieron como marco para describir el accionar social y político de organizaciones sociales vinculadas con la lucha por la vivienda y titularización de tierras en asentamientos irregulares. El caso del proyecto para la Radicación de la Villa 31 presentado en 1972, propulsado por delegados barriales y organizaciones villeras ligadas al peronismo, ejemplifica cómo el conflicto por la permanencia y el acceso a infraestructuras básicas se configura y proyecta como un derecho (Camelli \& Snitcofsky, 2016). La toma de tierras por parte de pobladores en La Victoria (Chile) transforma el repertorio de acción colectiva asociado con el problema de la vivienda y posiciona a la dinámica expulsiva del mercado del suelo como un terreno central para pensar identidades políticas de izquierda (Cortés, 2014; Touraine, 1987). El derecho a la ciudad se desplegó tanto como consigna contestaria, como nodo a partir del cual actualizar la disputa por derechos sociales (Ziccardi, 2016).

La serie de transiciones democráticas, que transformó el paisaje político de América Latina a comienzos de 1980, sirvió para promover el trabajo y las demandas de una pluralidad de movimientos urbanos y colectivos sociales que habían sido perseguidos y silenciados por dictaduras militares en la región (Oszlak, 1991). Con el advenimiento de las reformas institucionales y la recuperación de derechos civiles y políticos en países como Brasil, Argentina y Uruguay, la cuestión urbana resurgió como una dimensión constitutiva y fundacional de los nuevos regímenes democráticos (Portes \& Roberts, 2005). Las demandas acumuladas de tierra y vivienda fueron rápidamente incluidas en la larga lista de expectativas asociadas con territarias 41

277 
la consolidación del Estado de Derecho en la región (Cravino, 2009b). La ciudad, como delimitación geográfica, fue configurada como una plataforma ideal sobre la cual relegitimar prácticas civiles que habían sido brutalmente canceladas y en torno a la cual inventar nuevas expresiones y contenidos políticos. En Río de Janeiro hacia finales de los 70, por ejemplo, organizaciones barriales apoyadas por asociaciones religiosas y partidos de izquierda comenzaron a articular la presencia política de las favelas como el caso de Vila Brasil a nivel municipal (Gay, 1994). En el caso de San Pablo, la articulación de organizaciones vinculadas con ocupaciones de tierras y edificios propició la articulación de movimientos centrados en la expansión de derechos, que da formas prácticas a lo que Holston (2019) denomina como ciudadanías insurgentes.

El texto de Lefebvre proveyó durante los 80 simultáneamente un marco interpretativo de nuevas modalidades de acción colectiva y un mapa programático para una multiplicidad de actores no estatales que utilizaron el territorio y la ciudad como una plataforma para proyectar sus proclamas sociales y democráticas (Cravino, 2009a). Las demandas acumuladas por la vivienda y la tierra ponen en cuestión a los instrumentos modernos de política pública urbana e imponen la necesidad de actualizar y alinear la agenda democrática incorporando actores y derechos vinculados con la construcción del hábitat urbano. De movimientos sociales urbanos a redes de alianzas cooperativas para la construcción de viviendas, de organizaciones continentales para la vivienda social, federaciones de barrios y la proyección a escala de demandas comunales a la emergencia de nuevas agendas académicas regionales como las propuestas por Clacso, IEED-AL o el CEUR, la ciudad sirvió como soporte tanto para graficar la escala de los agudos conflictos socioespaciales, como para impulsar una nueva agenda de estudios sociales, que encontró en el accionar de grupos urbanos un medio para cuestionar los márgenes y el contenido de la nueva institucionalidad democrática.

En Quito, por ejemplo, a comienzos de los 80, emergieron una serie de agrupaciones barriales que tras invasiones $y$ ocupaciones de tierras, como las promovidas por el Comité de la Lucha de los Pobres, buscaron - el caso de la Unión de Organizaciones Barriales de Quito es emblemático- articularse con federaciones zonales y regionales para poder extender y proyectar sus demandas a nivel municipal y nacional (Carrión, 1988). En los "conos" de Lima, Cuaves (Comunidad Urbana Autogestionaria de Villa "El Salvador"), a la sombra de los procesos de izquierda peruanos, experimenta con la autogestión en la producción del hábitat. En Buenos Aires, el Movimiento de Ocupantes e Inquilinos, amparados por la Ordenanza de Radicación (que revertía la política de desalojo y erradicación aplicada durante la dictadura) incluyó a la ocupación de edificios en áreas centrales como en San Telmo, como forma de expandir el repertorio de acción colectiva y avanzar hacia 
la materialización del derecho a la ciudad (Rodríguez, 2009).

La expansión del repertorio de tácticas territoriales por parte de movimientos sociales urbanos durante la década del 80 y principios de los 90 acumuló conquistas - como el reconocimiento a la posesión y ocupación de tierras (Clichevsky, 1990)y retrocesos, en cuanto a los impactos e injusticias derivados de procesos de gentrificación vinculados con grandes proyectos urbanos y la proliferación de barrios cerrados (Cuenya, 2009; Janoschka, 2002; Roberts \& Portes, 2006). La configuración movimientista del derecho a la ciudad está centrada en una estructuración de la demanda urbana que posiciona a los movimientos sociales urbanos como iniciadores y agentes catalizadores de la protesta y a los Estados centrales y locales como receptores excluyentes.

La persistencia en la lucha por corregir los impactos de las injusticias espaciales tanto las heredadas, como las producidas por los nuevos regímenes democráticos municipales permitieron instalar y resaltar dos limitaciones centrales que se desprendían de las políticas del suelo existentes. Por un lado, el desafío y la necesidad de reconocer a los movimientos sociales urbanos y sus prácticas territoriales como interlocutores legitimados para zanjar las grietas entre la protesta social y la institucionalidad democrática (Holston, 2008). Por el otro, la urgencia por desarrollar un nuevo lenguaje de políticas públicas urbanas que permita reparar y contener un proceso de segregación e inseguridad espacial, que en ese entonces se aceleraba en las metrópolis Latinoamericanas (Caldeira, 2000).

\section{La institucionalización del derecho a la ciudad: de Lefebvre a Laclau}

A mediados de la década de los 80 , como una forma de incorporar institucionalmente la expansión de movimientos sociales urbanos y atender al menos de forma parcial a las demandas por una mayor justicia espacial en las ciudades latinoamericanas, la noción del derecho a la ciudad dejó de estar exclusivamente asociada a expresiones contestatarias y autónomas para pasar a formar parte de la articulación de un nuevo lenguaje burocrático-institucional, tendiente a reconfigurar la lógica de formulación de políticas públicas urbanas (Rolnik, 2011). Al mismo tiempo que se consolidaban nuevos repertorios de activismo urbano que encontraban en la construcción, el cooperativismo y la horizontalidad nuevos medios para pensar y hacer política urbana (Sitrin, 2012), una serie de innovaciones normativas buscaron institucionalizar el concepto del derecho a la ciudad en la región. El concepto, que en sus orígenes buscaba delimitar y resaltar prácticas autónomas de producción del espacio social, pasaba ahora a utilizarse como una plataforma para expandir la esfera de derechos civiles y sociales resguardada por los nuevos regímenes democráticos (Sugranyes \& Mathivet, 2011). La apropiación y traslación normativa del territarias 41 279 
derecho a la ciudad amparan y legitiman institucionalmente un largo derrotero de luchas sociales, reconocen la centralidad del conflicto propiciado por la dinámica del suelo en las ciudades y consolidan la problemática del suelo más allá del derecho a la vivienda digna, incorporando a la administración de las plusvalías generadas por procesos de regeneración urbana y a la participación en la producción social del espacio, las dimensiones centrales de la política urbana (Smolka, 2013). Sin embargo, como se detallará más adelante, este reconocimiento se hace a partir de un desplazamiento de la tríada conceptual sobre la cual Lefebvre había construido y justificado la noción del derecho a la ciudad.

En la región, la apropiación normativa del derecho a la ciudad inicia formalmente con la constituyente brasileña (1987-88) y atraviesa una larga década con innovaciones y consolidaciones como la instrumentación de la Ley 388 en Colombia sobre la recuperación de plusvalías urbanas, continúa con la reforma constitucional venezolana y el impulso a los Comités de Tierra Urbana, la redacción del estatuto de las ciudades en Brasil en 2001, la nueva constitución ecuatoriana (y su código de ordenamiento territorial, COOTAD) y las leyes de ordenamiento del suelo en la Provincia de Buenos Aires (2012) y Ecuador, para luego adquirir escala continental y mundial con la redacción de la Carta Internacional sobre el Derecho a la Ciudad, producida en Quito en 2004 y luego ratificada en Barcelona con el apoyo de Naciones Unidas y el Foro Urbano Mundial (Mayer, 2010). Así, la promoción del derecho a la ciudad y, junto con ello, el impulso de políticas públicas urbanas para ciudades "más justas, sostenibles y democráticas", cimentaron una alianza de principios entre municipios, agencias públicas nacionales y organismos internacionales. Durante ese lapso, a través de diferentes escalas de gobierno, se comienza a movilizar la noción del derecho a la ciudad como un marco conceptual lo suficientemente amplio como para contener una multiplicidad de iniciativas tributarias, sociales y de financiación de viviendas.

Centralmente, las innovaciones normativas tendieron a construir e inscribir una noción de propiedad en donde la dimensión social y medioambiental adquiriesen un lugar preponderante (Fernandes, 2006). La apropiación normativa del derecho a la ciudad buscó por un lado limitar la explotación del suelo urbano como un medio de aceleración de acumulación de capital y, por el otro, reconfigurar el momento de producción del espacio urbano no como una instancia exclusivamente determinada por la inversión privada, sino como un medio a partir del cual pensar mecanismos distributivos y de compensación (Clichevsky, 2012). Los debates teóricos y experiencias presentadas por organizaciones sociales se tradujeron en dos tipos de reglamentaciones: 1. Las normativas generales intentaron reconocer el rol de los actores sociales en la producción de la ciudad, la recuperación y ampliación del acceso al suelo público 
y la creación de nuevas instituciones para pensar el gobierno democrático de las ciudades, y 2. Asociar la figura del derecho a la ciudad con la capacidad de plasmar instancias redistribuidas que busquen aliviar las injusticias espaciales. Para ello, se crearon una serie de instrumentos que buscaron capturar las plusvalías derivadas de la especulación inmobiliaria.

En relación con la asociación del derecho a la ciudad como un derecho social fundamental y la elaboración de parámetros normativos para determinar las responsabilidades públicas con relación a la producción del hábitat se debe mencionar la Ley 14449 de la Provincia de Buenos Aires, promulgada en 2012. La ley obliga a los municipios de la provincia a tener un registro actualizado del déficit habitacional en las localidades, garantizar el uso social de la propiedad y reinstala la provisión universal de servicios e infraestructuras como una responsabilidad pública. En la normativa, el derecho a la ciudad aparece como un "principio rector" para el ordenamiento del suelo. De la misma manera aparece en la Ley Orgánica de Ordenamiento Territorial y Gestión del Suelo de 2015. Al detallar cómo se entiende el derecho a la ciudad en la normativa, esta repite dos apartados mencionados en la ley de la provincia de Buenos Aires: la regulación de la función social de la propiedad y la gestión democrática de la producción del hábitat.

En relación con la asociación del derecho a la ciudad con la inscripción de formas de urbanización redistributivas, la búsqueda de las reglamentaciones colombianas por capturar y distribuir el valor de propiedad generado a través de intervenciones públicas ejemplifica la asociación entre el derecho a la ciudad y la instrumentación de una visión de propiedad social, que encuentra en la figura de la plusvalía una forma de problematizar la protección absoluta de la propiedad privada sobre la tierra a la hora de pensar nociones de igualdad y justicia social en procesos urbanos contemporáneos (Smolka, 2013). En la misma dirección, la promulgación del Estatuto de la Ciudad en Brasil representa un punto de inflexión a la hora de ligar la invención de instrumentos tributarios y regulatorios con la inscripción y divulgación de una noción expansiva y multidimensional de propiedad (Fernandes, 2007). En 2001, como una plataforma normativa que apuntalaría la labor de lo que sería el Ministerio de Ciudades, creado durante la primera gestión del gobierno de Lula en 2003, el Estatuto de las Ciudades cierra un hiato regulatorio de más de una década instrumentando una serie de principios esbozados durante la constituyente brasileña del 87-88 (Friendly, 2013). El estatuto buscó atender, de manera simultánea, la necesidad imperiosa de los moradores de las favelas que buscaban poder resguardar el esfuerzo de autoconstrucción acumulado durante décadas y obtener un título legal, y el control en las grandes ciudades de un mercado inmobiliario en marcada aceleración, a través de la captura de plusvalía por inversión pública, falta de edificación y derechos de construcción. A su vez, estas territarios 41

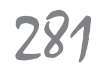


transformaciones tributarias sirvieron de precedentes para una serie de reformas en la región como la Ley de Desarrollo Ordenado y Sustentable uruguaya (2008) y la Ley de Plusvalía de la provincia de Buenos Aires (2012).

La traslación al ámbito institucional del derecho a la ciudad buscó articular como un todo coherente tanto soluciones de emergencia como el avance de la regularización de asentamientos informales con intervenciones distributivas capaces de promover un proceso de desarrollo urbano más justo y equitativo. Sin embargo, este avance normativo en la región se desplegó de forma paradojal. Al mismo tiempo que se acumularon instrumentos institucionales que permitían atender las consecuencias sociales y físicas de un proceso de urbanización desigual (Borsdorf \& Hidalgo, 2008), las propias modalidades de acumulación urbana y las cíclicas crisis fiscales llevaron a gobiernos municipales y estaduales a habilitar la diseminación de una serie de intervenciones urbanas como tipologías exclusivas (barrios cerrados, clubes de campo) (Prévot Schapira, 2000; Svampa, 2001) y grandes proyectos urbanos (Cuenya, 2009) que, lejos de contrarrestar procesos de injusticia espacial, tendieron a multiplicarlos y acentuarlos (Janoschka, 2002).

La reconfiguración normativa del derecho a la ciudad lo instala institucionalmente como horizonte programático y liga a la producción social del espacio urbano como una dimensión inescindible de una ciudadanía social expandida (Rolnik,
2014). Sin embargo, al mismo tiempo que se articularon nuevas formas de imaginar la responsabilidad pública a la hora de regular los procesos de urbanización en la región, los arreglos normativos se distanciaron de la tríada de proposiciones esgrimidas por Lefebvre en El derecho a la ciudad. Si bien la bandera del derecho a la ciudad sirvió para inscribir una serie innovadora de mecanismos participativos, particularmente en lo referido al involucramiento de la población en la definición de presupuestos locales (Goldfrank, 2006), salvo en el caso de la legislación generada a partir de la profunda crisis económica del 2001, que ampara a las fábricas recuperadas en la Argentina (Ruggeri,Novaes \& Sardá de Faria, 2014; Sitrin, 2012) y los avances en torno a la economía popular en Ecuador, el principio de autogestión no fue seriamente contemplado en la consagración normativa del derecho a la ciudad. Tampoco se percibió un avance en la posibilidad de iniciar procesos de desmercantilización como los sugeridos por Lefebvre. Si bien la captura de plusvalías y el desaliento a la especulación económica con tierras urbanas supusieron un intento creativo por corregir las desigualdades propiciadas por un proceso de urbanización acelerado, la forma en la que se promovió la noción de propiedad social no llega a rescatar la centralidad asignada al valor de uso del suelo y lo construido presentados en la obra de Lefebvre (Purcell, 2002).

La institucionalización del derecho a la ciudad sirvió más para contener bajo una misma bandera una serie de demandas 
sociales dispersas, que para cumplimentar las proyecciones de emancipación con las que había emergido el concepto. Especialmente para los nuevos gobiernos y partidos de izquierda que se consolidaron tras el derrumbe del sueño neoliberal en la región (Panizza, 2005), el derecho a la ciudad es movilizado para contener una problemática urbana que las reformas institucionales democráticas no habían logrado atender: una consigna, que si bien propició importantes alianzas entre movimientos sociales y partidos políticos (Zibechi, 2012), en la mayoría de los casos se mostró incapaz de iniciar el tipo de "metamorfosis radical" proyectada por Lefebvre. La transfiguración operada sobre el concepto de derecho a la ciudad durante la etapa normativa y la distancia impuesta con la tríada conceptual original propuesta por Lefebvre se transcribe a su vez como una transición teórico-práctica, en que nuevas prácticas políticas permiten revisar y alterar el poder significante del término. Si la emergencia de nuevas prácticas y colectivos urbanos de fuerte perfil autonomista, con una clara apertura hacia la promoción de experiencias de autogestión, se percibe como un intento por traducir el derecho a la ciudad como una plataforma a partir de la cual desenvolver una transformación radical de la vida cotidiana, la apropiación institucional-burocrática y su traslación normativa instalan una visión contrapuesta de política urbana. En ella el derecho a la ciudad pasa a referenciar un tiempo futuro mediado por ritmos burocráticos y de formulación de políticas públicas en donde el concepto se transforma en un significante vacío: se impone como un nodo discursivo que permite, por un lado, conjugar demandas particulares dispersas y, por el otro, trazar una diferenciación ideológica y programática. En esta nueva configuración del término, el derecho a la ciudad consagra a la articulación como práctica política urbana. Señala el relanzamiento de las agencias públicas locales, nacionales e internacionales como centros privilegiados para la formulación e implementación de intervenciones urbanas y como engranajes indispensables para pensar el arreglo de nuevas mayorías electorales.

La articulación, en Laclau, es una operación política que se cristaliza, aunque no se acaba, en una disrupción del lenguaje: "Llamamos articulación a cualquier práctica que establece una relación entre elementos de modo que su identidad se vea modificada como resultado de la práctica articuladora" (Laclau \& Mouffe, 2001, p. 105). La articulación aglutina una serie de intervenciones a través de una práctica discursiva que establece equivalencias entre reclamos fragmentados, en las que los elementos heterogéneos y las demandas particulares se reconfiguran a partir de la inscripción hegemónica de un nombre que permite trazar y delimitar los márgenes políticos de pertenencia y oposición.

Particularmente para los gobiernos de Lula, Chávez, Mujica, Morales y Correa y la nueva izquierda latinoamericana, el derecho a la ciudad fue utilizado como una manera de delimitar y construir una crítica a lo que de distinta manera percibieron territarios 41

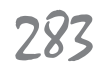


como los impactos sociales de una acelerada urbanización neoliberal (Harnecker, 2015; Sugranyes, 2010). El derecho a la ciudad se movilizó dentro del ideario progresista de la región, como un soporte sobre el cual tejer y actualizar una alianza con amplios sectores populares urbanos, $\mathrm{y}$ oponer - al menos en términos simbólicos- las legítimas demandas de las clases subalternas a los intereses de facciones locales e internacionales ligadas al desarrollo del sector inmobiliario, sectores concentrados de la construcción y partidos políticos opositores. Para la nueva izquierda de la región, el derecho a la ciudad buscó interpelar a los desposeídos y a las nuevas clases medias urbanas proyectando la universalización de la regularización de la tenencia de tierras, la expansión de la participación ciudadana en el gobierno de la planificación de la ciudad y una distribución de los beneficios derivados de la urbanización. La centralidad asignada al derecho a la ciudad permitió iluminar las consecuencias sociales de un proceso de urbanización signado por la fragmentación espacial, la precarización del hábitat y una persistente desigualdad en el acceso a infraestructuras básicas (Maeckelbergh, 2016).

\section{La prefiguración y el derecho a la ciudad}

Traducido en instrumentos, la interpretación normativa del derecho a la ciudad hizo hincapié en la participación ciudadana, el intento por distribuir los beneficios derivados del proceso de urbanización (plusvalías) y la regularización de las prácticas de materialización popular. Tanto en los instrumentos de implementación privilegiados (impuestos, prestaciones financieras para atender la demanda de vivienda, subsidios para el desarrollo de la oferta de vivienda), como en las secuencias y ritmos operativos que signaron la batería de intervenciones urbanas vinculadas con la agenda del derecho a la ciudad, la configuración normativa reforzó la preeminencia de la institucionalidad pública, los mecanismos representativos y la temporalidad inherente a los procesos de formulación e implementación de políticas públicas urbanas (Holloway, 2010; Yates, 2015; Zibechi, 2012).

Sin embargo, para una pluralidad de movimientos sociales y colectivos urbanos - motivados por las limitaciones evidenciadas por las instancias de gobierno local para responder y materializar formas de producción del espacio urbano más inclusivas- resultó imperativo recuperar las coordenadas originales esbozadas por Lefebvre para experimentar con nuevas modalidades de autogestión y prefigurar, sin la mediación de las agencias públicas, soluciones prácticas para las necesidades materiales y espaciales de las periferias urbanas de la región.

En intersticios abandonados, en edificios recuperados, en galpones, plazas y barrios marginales; en centros comunitarios, en casas con extensiones improvisadas o escuelas populares, sobre infraestructuras y redes autogestionadas, una serie 
heterogénea de actores urbanos - forzados por una creciente erosión de las identidades sociales vinculadas con el mundo del trabajo en fábricas y las prácticas asociativas del espectro sindical (Svampa \& Pereyra, 2009) - comenzaron a problematizar la hegemonía del Estado y la lógica del capital para determinar los medios, formas asociativas e instrumentos financieros disponibles para producir el espacio urbano. A través de intervenciones físicas, construcciones y plataformas asociativas autónomas se acelera un retiro hacia los territorios periféricos, poniendo en cuestión el lenguaje, los sujetos involucrados y los alcances de las intervenciones públicas urbanas vinculadas con el derecho a la ciudad. Propulsados por los fracasos de las políticas de vivienda y la irrefrenable privatización del territorio como táctica de acumulación (Brenner \& Schmid, 2014), movimientos sociales, grupos vinculados con la arquitectura y la construcción, comités barriales y académicos tejieron nuevas alianzas urbanas con el objetivo de actualizar los contenidos y los repertorios necesarios para materializar el derecho a la ciudad.

Disímiles en su alcance, fragmentadas y vinculadas con diversos aspectos de la vida cotidiana, estas intervenciones plantean una nueva configuración del derecho a la ciudad. Son intervenciones signadas por la emergencia y la desposesión (Harvey, 2007) y se orientan a resolver — de forma material y física- problemáticas puntales y singulares (Holloway, 2010). La conquista de espacios institucionales de poder no aparece como horizonte programático primordial; en todo caso, se plantean como un corolario derivado de experimentaciones y conquistas acumuladas. Las intervenciones se presentan como una instancia disruptiva: una interrupción en la forma de organizar y regular prácticas y espacios cotidianos para instalar - en su reemplazo - formas más inclusivas, dinámicas y no comodificadas de hacer ciudad (Sitrin, 2014). Algunas de ellas desplegadas por organizaciones sociales establecidas con fuerte arraigo territorial y otras impulsadas por vecinos que arreglan lazos de asociación para lograr alterar patrones establecidos de carencia y marginalidad. Las intervenciones buscan articular redes de solidaridad, extender un catálogo de posibilidades con resoluciones técnicas y construir una cadena de espacios de libre acceso, donde se registren y proyecten saberes locales y proliferen nuevas formas de intercambio.

Esta serie de intervenciones autónomas que abren un proceso de construcción de identidades sociales y políticas al margen de los ritmos y regulaciones institucionales formales propulsó - dentro de la literatura de los movimientos sociales y los estudios urbanos - una revisión de la noción de prefiguración (Minuchin, 2016). En todos los casos existe un intento por alterar los márgenes de lo posible, abriendo una temporalidad para la política urbana que no está regulada por las cadencias y secuencias inherentes a los instrumentos de planificación pública. La proyección del futuro como espacio y tiempo imaginado territarios 41

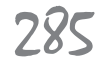


- como horizonte utópico donde se concretan las transformaciones- se disloca para instalar al presente y a la experimentación como terreno y lenguaje de la acción política urbana (Dinerstein, 2014). En esta nueva configuración del derecho a la ciudad se vislumbra una dispersión de la agencialidad política: una recuperación por parte de comunidades, asociaciones y movimientos de la praxis como instancia constitutiva de la subjetividad urbana: el hacer, la construcción, la mediación material expanden los repertorios de la contestación y fuerzan una actualización del activismo urbano como práctica cotidiana. Como ejemplo, se puede citar el caso del partido urbano Ciudad Futura en Rosario (Argentina), que busca proyectar su programa político a partir de la prefiguración de materializaciones productivas y culturales: escuelas de gestión social, fábricas lácteas y la producción de contenidos culturales se articulan sin la mediación ni la institucionalidad de las agencias públicas locales o provinciales. Esta recuperación de la capacidad para transformar y hacer supone una revisión y expansión de las lógicas de participación pasiva como la que se despliega en la conformación de presupuestos participativos locales. Como señala Ouviña (2013):

[c] on variadas iniciativas, miradas e inserciones en sus respectivos territorios, muchos de estos movimientos latinoamericanos comparten una vocación común por reinventar la praxis política, a través de la apelación a la horizontalidad, la solidaridad, la conciencia crítica y el despliegue de diversas acciones de autoorganización territorial (p. 78).

La apropiación de este lenguaje práctico por parte de nuevos colectivos urbanos supone un pasaje y una transformación en los modos de pensar el activismo urbano y la protesta. La consolidación de la prefiguración como práctica política proyecta una doble crítica sobre las interpretaciones normativas y burocráticas del derecho a la ciudad y expande el alcance y repertorio de la acción colectiva vinculada con asuntos territoriales. Por un lado, cuestiona la representación y mediación institucional como registro hegemónico para pensar la formulación e implementación de políticas públicas urbanas. Por el otro, y de forma simultánea, asocia el hacer y la praxis con la inscripción de espacialidades que no estén estructuradas en torno a la lógica de la acumulación de capital, privilegiando formas de inscribir circuitos donde prime el valor de uso. El despliegue del repertorio tradicional para la protesta anclado en marchas, ocupaciones, paros y piquetes se expande para encontrar en la materialización y la praxis un medio para actualizar el acto y los contenidos de la protesta.

Como concepto, la prefiguración tiene un fuerte arraigo en la tradición marxista y adquiere relevancia a fines de los años 60 para caracterizar las prácticas anarquistas y feministas que buscaban una transformación radical de la vida cotidiana (Boggs, 1977; Maeckelbergh, 2011). La prefiguración marcaba una crítica a las teorías del 
cambio. La acción no debía estar orientada hacia transformaciones radicales futuras, subordinadas a la conquista total de la burocracia estatal, sino en el hacer cotidiano, en la alteración de las relaciones que regulan las prácticas de sociabilidad e intercambio en los espacios en donde se negocian, arreglan y despliegan las identidades. En este sentido, existe un punto de contacto entre el interés mostrado por Lefebvre en delimitar la politicidad de los momentos cotidianos y la centralidad que adquiere la praxis dentro de posiciones prefigurativas.

Con la consolidación de redes de movimientos antiglobalización y antiausteirdad, la prefiguración vuelve a instalarse como eje de debate para la teorías de la acción colectiva (Yates, 2015). Las nuevas contribuciones ponen el énfasis en la construcción de espacialidades en donde la autogestión y la descomodificación dejan de ser enunciados programáticos y pasan a ser experimentos del presente, que alteran - aunque no sea más que de forma circunscripta y limitada en el tiempo- la forma de concebir y practicar lo cotidiano. Como lo señala Maeckelburgh (2011), "practicar una política prefigurativa supone remover la distinción temporal entre los desafíos del presente y los objetivos del futuro; plantea, en cambio, que los desafíos y los objetivos, lo real y lo ideal, se vuelvan uno en el presente" (p. 4).

La reaparición de la prefiguración como práctica política hace fuerte hincapié en la recuperación de la politicidad del momento constructivo. Lejos de caer preso de las viejas imaginaciones modernistas que subordinaban procesos de cambio social a un determinismo espacial, las alianzas sociales que se tejen en torno a la prefiguración en la región utilizan la materialización y la espacialidad como prácticas y lenguajes a partir de los cuales pensar y experimentar lazos asociativos y productivos alternativos (McGuirk, 2014). La construcción como dimensión central de una política prefigurativa es parte de un nuevo repertorio de acción colectiva a partir del cual desplegar y articular, revisar y adecuar identidades locales, lógicas de pertenencia y modalidades organizativas. La prefiguración pone en cuestión la hegemonía de las agencias públicas para alterar la territorialidad cotidiana y problematiza la temporalidad de la acción política urbana (Harvey, 2000).

Desde la creación de espacios comunitarios hasta la construcción de escuelas populares o infraestructuras básicas para emplazar mercados y regímenes de intercambio, la prefiguración como práctica requiere de una instancia de invención físico-material. Este es el caso, por ejemplo, de la Corriente Villera Independiente que trabaja e interviene en una pluralidad de asentamientos en Buenos Aires desde 2012. El colectivo, conformado mayoritariamente por vecinos, despliega lógicas autogestivas para producir soluciones infraestructurales de escala barrial: desde cloacas hasta centros comunitarios, desde cooperativas de agua hasta espacios de capacitación. El movimiento se articula en torno a la diseminación de formas de territarias 41

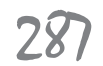


autogobierno, buscando - como lo mencionan en su análisis l'Huillier y Ouviña (2016) -

contribuir a la construcción de una agenda en común, que dinamice proyectos concretos en pos de democratizar la toma de decisiones en torno de los espacios públicos y comunitarios, sin dejar de construir y potenciar los embriones de poder popular en cada territorio donde se encuentran presentes (p. 75-6).

En América Latina, la revisión conceptual de la prefiguración permite iluminar la emergencia de nuevas subjetividades políticas urbanas. Por ejemplo, en contraposición a la figura del activista que acompañó las experiencias militantes durante la etapa movimientista del derecho a la ciudad, en donde la posición subjetiva del militante estaba construida en torno a regímenes de pertenencia claramente delimitados y cerrados, en la nueva configuración del derecho a la ciudad vemos que los repertorios utilizados llevan a revisar el tipo de acción $\mathrm{y}$ actores asociados con movimientos sociales urbanos. En este sentido, es interesante analizar cómo grupos y colectivos vinculados con la arquitectura social, por ejemplo, cuestionan las lógicas de producción profesional - centralmente orientadas hacia la comodificación del espacio- y trabajan sobre formas no mercantiles de pensar la generación y construcción de espacios comunitarios. Así, por ejemplo, el estudio PICO, apoyado por la comisión presidencial del Movimiento por la Paz y la Vida de Venezuela, trabaja en el diseño, desarrollo y construcción - junto a otros profesionales y comunidades periféricasde una batería de intervenciones públicas que busca diseminar una serie de infraestructuras de inclusión que garantice la aparición, circulación y expresión de los que no tenían voz ni derechos. Aquí, el momento constructivo no aparece como un fin en sí mismo, sino para prefigurar una recomposición de lo público: una recuperación de lo común, en la cual la agencialidad política retorna a las comunidades y se inscriben zonas urbanas gobernadas por lógicas del valor de uso.

La materialización, como manifestación prefigurativa, actualiza la noción del derecho a la ciudad. Su significación se aleja del plano normativo para pasar a describir actos y manifestaciones performativas. Ahora bien, no toda manifestación de autosuficiencia o autoconstrucción constituye una expresión prefigurativa. En este sentido, como bien lo señala Holloway (2010), la mera condición de desposesión, la experimentación cotidiana de formas de explotación no cualifica como una práctica de resistencia. La disrupción aparece en torno a los intersticios, "los cracks, espacios o momentos en donde rechazamos la autoridad externa y afirmamos el 'acá y ahora mandamos'” (Holloway, 2010, p. 23). La prefiguración no debe pensarse como restringida a lo eventual: la experimentación no solo opera sobre la inmediatez de una falta o una carencia, sino que se presenta a su vez como una forma de cuestionar el lenguaje y las tecnologías de gobierno 
imperantes. Introduce una temporalidad que no está regulada por los ritmos institucionales, pero que puede proyectarse en escala a partir del establecimiento de redes asociativas y federaciones de grupos y colectivos sociales. En este sentido, las redes regionales de vivienda o la Federación de Cooperativas Uruguayas se pueden leer como articulaciones en escala de prácticas prefigurativas singulares.

\section{Conclusiones}

La historia conceptual del derecho a la ciudad en América Latina estuvo signada por las tensiones y disputas derivadas de los esfuerzos por su materialización. Su historia es al mismo tiempo una actualización de los repertorios utilizados por colectivos sociales y agencias públicas por problematizar los modos de hacer ciudad y los esfuerzos teóricos por adaptar la extensión y el potencial significante del término. Es por ello que la historia del derecho a la ciudad es una historia abierta de invenciones, acumulaciones, superposiciones, retrocesos y revisiones. La disputa por la significación del derecho a la ciudad en América Latina ilustra la capacidad de distintos actores de problematizar, independientemente de su lugar en la arena política, los márgenes de lo posible dentro de la esfera de intervenciones urbanas. Con el desandar del derecho a la ciudad se expandieron los modos de pensar la participación social en la producción del espacio urbano y se problematizaron los dominios y las potestades disponibles para transformar territorios.

El artículo presentó a modo de hipótesis un aporte historiográfico para comprender cómo se articulan y desplazan configuraciones conceptuales: cómo un término nace para nombrar y describir determinadas prácticas políticas y pasa a contener proposiciones o intervenciones muchas veces antagónicas o disímiles. En este sentido se presentaron de manera analítica tres grandes configuraciones que, si bien no se desenvuelven de forma lineal, van ganando relevancia en torno a transacciones y eventos políticos puntuales. Para la construcción de estas configuraciones, se propuso introducir marcos y referencias teóricas complementarias que sirvieron para actualizar —en los debates académicos y en las esferas de formulación de políticas públicas- los márgenes significantes del derecho a la ciudad.

En primer lugar, se detalló una etapa movimientista en la que, desde la teoría el derecho a la ciudad se presentó la autogestión como una dimensión de las prácticas democráticas urbanas y el asunto de la vivienda como un medio para articular un marco de demanda contestatario. Como segunda configuración se describió la consolidación de una instancia normativo-burocrática asociada con la emergencia de gobiernos progresistas en la región, en donde se instala al derecho a la ciudad como nodo significante para articular posiciones hegemónicas. Capturado como consigna, se evidencia un pasaje 
de la autogestión a la articulación como práctica política dominante, plasmado en la instalación de los Estados centrales como agentes legitimados para actualizar los contenidos y límites del derecho a la ciudad. Como respuesta a este proceso normativo, que encontró serias limitaciones a la hora de recuperar la consigna de descomodificación esbozada por Lefebvre, el artículo detalla la cristalización de una nueva configuración del derecho a la ciudad, centrada en la práctica de la prefiguración.

La actualización del derecho a la ciudad a partir de la noción de prefiguración plantea un importante desafío a los gobiernos locales y a la maquinaria de gestión territorial. En un contexto en donde las administraciones locales -independientemente de su filiación ideológica- tienden a asociar desarrollo urbano con emprendimientos inmobiliarios, el llamado a recuperar tanto la agencialidad para demarcar espacios de gestión autónoma, como formas no mercantiles de producción del espacio ponen en cuestión no solo la legitimidad democrática de los modelos de ciudad propuestos, sino las alianzas socioeconómicas que reproducen los esquemas fiscales y presupuestarios locales. La prefiguración llama a actualizar las formas de concebir la participación en los asuntos territoriales, y a democratizar las formas de producir el espacio, y marca los limites a las formas de representación imperantes.

El artículo utiliza el derrotero conceptual y práctico del derecho a la ciudad para plantear la posibilidad de abrir una historiografía de la cuestión urbana que, lejos de plantear como compartimentos estancos la transformación de los recursos teóricos utilizados para describir la mutación de los procesos de urbanización y el registro histórico de prácticas e intervenciones espaciales, introduzca la complementariedad y la codependencia entre ambos registros. El derecho a la ciudad, que surgió con coordenadas y principios teóricos consolidados, amplió su horizonte significativo tanto de la mano de nuevos aportes teóricos como mutaciones en los repertorios de acción colectiva. En este sentido, la historia del derecho a la ciudad deja de ser una compilación de las prácticas políticas desplegadas para materializar y dar sentido a un conjunto de demandas urbanas y se transforma en un espacio y discurso político-cultural, que incluye tanto la evolución de formas de acción colectiva como la invención de nuevos instrumentos de políticas públicas como marcos teóricos interpretativos.

\section{Referencias}

Boggs, C. (1977). Marxism, prefigurative communism, and the problem of workers' control. Radical America, $11(6), 12$.

Borsdorf, A., \& Hidalgo, R. (2008). New dimensions of social exclusion in Latin America: From gated communities to gated cities, the case of Santiago de Chile. Land Use Policy, 25(2), 153160. Doi: https://doi.org/10.1016/j. landusepol.2007.04.001 
Brenner, N., Marcuse, P., \& Mayer, M. (Eds.). (2012). Cities for people not for profit: critical urban theory and the right to the city. London: Routledge.

Brenner, N., \& Schmid, C. (2014). The 'urban age' in question. International Journal of Urban and Regional Research, 38(3), 731-755. Doi: https:// doi.org/10.1111/1468-2427.12115

Caldeira, T. (2000). City of walls: Crime, segregation, and citizenship in São Pablo. London: University of California Press.

Camelli, E., \& Snitcofsky, V. (2016). Primer plan de radicación para la Villa 31 : un antecedente a la defensa del derecho a la ciudad en Buenos Aires (1972-1974). Quid, 16(6), 27-46. Recuperado de http://hdl.handle.net/11336/67223

Carrión, F. (1988). La urbanización andina: notas sobre el estado del conocimiento. En F. Carrión (Coord.), Investigación urbana en el Área Andina (pp. 11-44). Quito: Centro de Investigaciones/IFEA.

Carrión, F., \& J. Erazo. (2016). El derecho a la ciudad en América Latina. México D.F.: Universidad Nacional Autónoma de México.

Clichevsky, N. (1990). Sobre la planificación urbana posible en los ochenta: el caso del área metropolitana de Buenos Aires. Ciudad y Territorio (86-87), 513-524.

Clichevsky, N. (2012). Acceso a la tierra urbana y políticas del suelo en el Buenos Aires metropolitanos. Apuntes para la reflexión. RIURB, 8, 59-72. Recuperado de http://hdl.handle. net/2099/13034
Cortés, A. (2014). El movimiento de pobladores chilenos y la población La Victoria: ejemplaridad, movimientos sociales y el derecho a la ciudad. EURE (Santiago), 40(119), 239-260. Doi: http://dx.doi.org/10.4067/S025071612014000100011

Cravino, M. C. (2009a). Entre el arraigo y el desalojo. La villa 31 de Retiro. Derecho a la ciudad, capital inmobiliario y gestión urbana. Buenos Aires: Universidad Nacional de General Sarmiento.

Cravino, M. C. (2009b). Territorialidades en las villas de la Ciudad de Buenos Aires. Estado, mercado y relaciones sociales en la espacialidad barrial. En A. Catenazzi, A. Quintar, M. C. Cravino, N. Da Representacao, \& A. Novick (Eds.), El retorno de lo politico a la cuestión urbana (pp. 45-78). Buenos Aires: Prometeo Libros.

Cuenya, B. (2009). Grandes proyectos urbanos latinoamericanos. Aportes para su conceptualización desde la perspectiva del gobierno local. Cuaderno Urbano, 8, 229-252.

Dinerstein, A. C. (2014). The politics of autonomy in Latin America: The art of organising hope. Londres: Palgrave Macmillan.

Fernandes, E. (2006). Updating the declaration of the rights of citizens in Latin America: constructing the right to the city in Brazil. International Public Debates: Urban Policies and the Right to the City, 40-53.

Fernandes, E. (2007). Constructing the right to the city in Brazil. Social e Legal Studies, territarios 41 291 


\section{territarias 41}

292
16(2), 201-219. Doi: https://doi. org/10.1177/0964663907076529

Friendly, A. (2013). The right to the city: theory and practice in Brazil. Planning Theory \& Practice, 14(2), 158-179. Doi: https://doi.org/10.1080/146 49357.2013.783098

Gay, R. (1994). Popular organization and democracy in Rio de Janeiro: A tale of two favelas. Philadelphia: Temple University Press.

Goldfrank, B. (2006). Los procesos de "presupuesto participativo" en América Latina: éxito, fracaso y cambio. Revista de Ciencia Politica (Santiago), 26(2), 3-28. Doi: http://dx.doi.org/10.4067/ S0718-090X2006000200001

Harnecker, M. (2015). A world to build: new paths toward twenty-first century socialism: NYU Press.

Harvey, D. (2000). Spaces of Hope. Edinburgh: Edinburgh University Press.

Harvey, D. (2007). Neoliberalism as creative destruction. The Annals of the American Academy of Political Science, 610(1), 21-44. Doi: https://doi. org/10.1177/0002716206296780

Harvey, D. (2012). Rebel cities: from the right to the city to the urban revolution. Londres: Verso Books.

Holloway, J. (2010). Crack capitalism. Londres: Pluto Press.

Holston, J. (2008). Insurgent citizenship: Disjunctions of democracy and modernity in Brazil. Princeton: Princeton University Press.
Holston, J. (2019). Metropolitan rebellions and the politics of commoning the city. Anthropological Theory, 19(1), 120-142. Doi: https://doi. org/10.1177/1463499618812324

l'Huillier, F., \& Ouviña, H. (2016). Del Indoamericano a la Carpa Villera. Derecho a la ciudad y luchas por la urbanización de las villas (2010-2016). Quid 16(6), 54-87.

Janoschka, M. (2002). El nuevo modelo de la ciudad latinoamericana: fragmentación y privatización. EURE (Santiago), 28(85), 11-20. Doi: http://dx.doi.org/10.4067/S025071612002008500002

Laclau, E., \& Mouffe, C. (2001). Hegemony and socialist strategy: towards a radical democratic politics. Londres: Verso.

Lefebvre, H. (1976). Espacio y politica. Barcelona: Península.

Lefebvre, H. (1978). El derecho a la ciudad. Barcelona: Península.

Lefebvre, H. (2003). The urban revolution. Minessota: University of Minessota Press.

Maeckelbergh, M. (2011). Doing is believing: Prefiguration as strategic practice in the alterglobalization movement. Social Movement Studies, 10(01), 1-20. Doi: https://doi.org/10.1080/1474 2837.2011.545223.

Maeckelbergh, M. (2016). From digital tools to political infrastructure. The SAGE Handbook of Resistance, 280.

Mayer, M. (2010). The 'Right to the City' in the context of shifting mottos of urban social movements. City: analysis if ur- 
ban trends, culture, theory, policy, action, 13(23), 362-374. Doi: https://doi. org/10.1080/13604810902982755

McGuirk, J. (2014). Radical cities: across Latin America in search of new architecture. Londres: Verso.

Merrifield, A. (2014). The new urban question. Londres: Pluto Press.

Minuchin, L. (2016). The politics of construction: Towards a theory of material articulations. Environment and Planning D: Society and Space, 34(5), 895-913. Doi:10.1177/0263775816634347

Nuñez, A. (2009). De la alienación al derecho a la ciudad. Una lectura (posible) sobre Henri Lefebvre. Theomai. Estudios sobre Sociedad y Desarrollo, (20). Recuperado de http://www.redalyc. org/articulo.oa?id=12415108004>

Oszlak, O. (1991). Merecer la ciudad: los pobres y el derecho al espacio urbano. Buenos Aires: Hvumanitas-Cedes.

Ouviña, H. (2013). La política prefigurativa de los movimientos populares en América Latina. Hacia una nueva matriz de intelección para las ciencias sociales. Acta Sociológica, 62, 77104. Doi: https://doi.org/10.1016/ S0186-6028(13)71000-4

Panizza, F. (2005). Unarmed utopia revisited: the resurgence of left-ofcentre politics in Latin America. Political Studies, 53(4), 716-734. Doi: https://doi.org/10.1111/j.14679248.2005.00553.x

Portes, A., \& Roberts, B. (2005). The freemarket city: Latin American urbanization in the years of the neoliberal experiment. Studies in Comparative International Development, 40(1), 43-82.

Prévot Schapira, M. (2000). Segementación, fragmentación, secesión: hacia una nueva geografía social del Aglomerado de Buenos Aires. Economia, Sociedad y Territorio, 2(7), 405-431.

Purcell, M. (2002). Excavating Lefebvre: the right to the city and its urban politics of the inhabitant. GeoJournal, 58, 99-108.

Roberts, B., \& Portes, A. (2006). Coping with the free market city: collective action in six Latin American cities at the end of the twentieth century. Latin American Research Review, 4I(2), 5783. Retrieved from https://www.jstor. org/stable/3874669

Rodríguez, M. C. (2009). Autogestión, politicas del hábitat y transformación social. Buenos Aires: Espacio Editorial.

Rolnik, R. (2011). Democracy on the edge: Limits and possibilities in the implementation of an urban reform agenda in Brazil. International Journal of Urban and Regional Research, 35(2), 239255. Doi: https://doi.org/10.1111/ j.1468-2427.2010.01036.x

Rolnik, R. (2013). Late neoliberalism: the financialization of homeownership and housing rights. International Journal of Urban and Regional Research, 37(3), 1058-1066. Doi: https://doi. org/10.1111/1468-2427.12062

Rolnik, R. (2014). Place, inhabitance and citizenship: The right to housing and the right to the city in the contemporary urban world. International Journal of Housing Policy, 14(3), 293-300. Doi: tersitarias 41 293 
https://doi.org/10.1080/1461671 8.2014.936178

Ruggeri, A., Novaes, H., \& Sardá de Faria, M. (Eds.). (2014). Crisis y autogestión en el siglo XXI. Buenos Aires: Ediciones Continente.

Schmid, C. (2011). Henri Lefebvre, the right to the city, and the new metropolitan mainstream. En N. Brenner, P. Marcuse, \& M. Mayer (Eds.), Cities for people, not for profit: Critical urban theory and the right to the city (pp. 5474). Londres: Routledge.

Sitrin, M. (2012). Everyday Revolutions: Horizontalism and Autonomy in Argentina. Londres: Zed Books.

Sitrin, M. (2014). Goals without demands: The new movements for real democracy. South Atlantic Quarterly, 113(2), 245-258. Doi: https://doi. org/10.1215/00382876-2643594

Smolka, M. (2013). Implementing value capture in Latin America: policies and tools for urban development. Cambridge: Lincoln Institute of Land Policy.

Sugranyes, A. (2010). El derecho a la ciudad. Praxis de la utopía. Hábitat y Sociedad, 2010,(1), 71-79. Doi: http:// dx.doi.org/10.12795/HabitatySociedad.2010.il.05

Sugranyes, A., \& Mathivet, C. (2011). Ciudades para tod@s: por el derecho a la ciudad, propuestas y experiencias. Habitat International Coalition.

Svampa, M. (2001). Los que ganaron: la vida en los countries y barrios privados. Buenos Aires: Biblos.

Svampa, M., \& Pereyra, S. (2009). Entre la ruta y el barrio. La experiencia de las organizaciones piqueteras. Buenos Aires: Biblos.

Swyngedouw, E. (2002). The strange respectability of the situationist city in the society of the spectacle. International Journal of Urban and Regional Research, 26(1), 153-165. Doi: https:// doi.org/10.1111/1468-2427.00369

Touraine, A. (1987). La centralidad de los marginales. Revista Proposiciones, 14, 217.

Yates, L. (2015). Rethinking prefiguration: Alternatives micropolitics and goals in social movements. Social Movements Studies, 14(1), 1-21. Doi: https:// doi.org/10.1080/14742837.2013. 870883

Zibechi, R. (2012). Territories in resistance: A cartography of Latin American Social Movements. AK Press.

Ziccardi, A. (2016). "Cuestion social y el derecho a la ciudad" En F. Carrión \& J. Erazo (Eds.), El derecho a la ciudad en América Latina (pp. 23-40). Ciudad de México: Clacso. 